\title{
Studies of Anopheles gambiae s.l (Diptera: Culicidae) exhibiting different vectorial capacities in lymphatic filariasis transmission in the Gomoa district, Ghana
}

\author{
Hilaria Amuzu', Michael D Wilson ${ }^{1,2}$, Daniel A Boakye ${ }^{1 *}$
}

\begin{abstract}
Background: Two lymphatic filariasis endemic communities Mampong and Hwida in Ghana have been regularly monitored for impact on transmission after annual mass drug administration (MDA) with albendazole and ivermectin. After six MDAs even though the ABR for Mampong was 55883/person/year and that of Hwida was 2494/person/year, they both had ATPs of 15.21 infective larvae/person/year. Interestingly the human microfilaraemia levels had reduced significantly from $14 \%$ to $0 \%$ at Mampong and $12 \%$ to $3 \%$ at Hwida. In an attempt to understand this anomaly, we collected mosquitoes over a 5 -month period using human landing catches to determine the species composition, the number of cibarial teeth, the lengths and widths of the cibarium and the cibarial dome of the vector populations.

Results: Out of 2553 mosquitoes caught at Mampong, 42.6\% were An. gambiae s.l. All 280 identified further by PCR were An. gambiae s.s (275 M and 5 S molecular forms). At Hwida, 112 mosquitoes were obtained; 67 (59.8\%) were An. gambiae s.l, comprised of 40 (59.7\%) An. melas, 24 (35.8\%) An. gambiae s.s (17 and $5 \mathrm{M}$ and S molecular forms respectively) and 3 (4.5\%) unidentified. The mean number of teeth for An. melas was 14.1 (median $=14$, range $=12-15)$, An. gambiae s.s., 15.7 (median $=15$, range $=13-19) \mathrm{M}$ form 15.5 (median $=15$ range $=13-19)$ and $\mathrm{S}$ form 16 (median $=16$, range 15-17). The observed differences in teeth numbers were significantly different between An. melas and An. gambiae s.s $(p=0.004)$, and the $M$ form $(p=0.032)$ and the $S$ form $(p=0.002)$.

Conclusions: In this study, An. gambiae s.s was the main vector at Mampong and was found to possess significantly more cibarial teeth than An. melas, the principal vector at Hwida. We postulate that the different impact observed after 6 MDAs may be due to An. gambiae s.s exhibiting 'facilitation' at Mampong and at Hwida An. melas the main vector exhibits 'limitation'. Thus it may be necessary to compliment MDA with vector control to achieve interruption of transmission in areas where An. melas may exhibit limitation.
\end{abstract}

\section{Background}

Lymphatic filariasis (LF) caused by infections with Wuchereria bancrofti is a debilitating disease which has adverse effects on productivity of infected persons and socioeconomic development of endemic countries [1]. The parasite is transmitted through the bite of infected mosquito species of various genera including, Culex, Anopheles and Aedes. In Ghana, members of the

\footnotetext{
* Correspondence: dboakye@noguchi.mimcom.org

'Department of Parasitology, Noguchi Memorial Institute for Medical Research, University of Ghana, P.O. Box LG 581, Legon, Accra, Ghana Full list of author information is available at the end of the article

An. gambiae species complex and An. funestus are the principal vectors [2-5] although An. pharoensis has been implicated as a vector [3]. Anopheles gambiae s.l. in Ghana comprises An. gambiae s.s (which has two molecular forms; $\mathrm{M}$ and S), An. melas and An. arabiensis [6-8]. Unlike in Asia and East Africa, the Culex species in Ghana are refractory to the parasite [4].

An important determinant of transmission of W. bancrofti is the ability of the mosquito to ingest and support the development of microfilariae ( $\mathrm{mf}$ ) [9]. This ability is compromised when the mosquitoes possess cibarial armatures or 'teeth' in the foregut that lacerate ingested 
$\mathrm{mf}[10]$ thus reducing the number of $\mathrm{mf}$ that could develop. However the extent of reduction will depend on the number of teeth; the higher the number the more effective the armature should be at reducing $\mathrm{mf}$ numbers. According to Mcgreevy et al., [10] pharyngeal armatures, spines and papillae present in the foregut of mosquitoes may pose some threat to ingested $\mathrm{mf}$ but the most lethal structure in the foregut is the cibarial armature.

The laceration of $\mathrm{mf}$ during ingestion by the mosquito is independent of the $\mathrm{mf}$ density in the human host blood [11] but it is more pronounced at low mf densities. This results in the phenomenon termed 'facilitation' which is a positive feedback mechanism exhibited by some mosquito vectors. In facilitation, the number of ingested $\mathrm{mf}$ developing to infective stage (L3) increases as the number of $\mathrm{mf}$ ingested increases [12,13]. Such vectors are efficient mainly at high microfilaraemia levels. It is postulated that in areas where mosquito species exhibit facilitation, it should be possible to eliminate lymphatic filariasis by interrupting transmission with mass drug administration (MDA) alone. Anopheles mosquitoes possess cibarial armatures which lacerate ingested $\mathrm{mf}[11,10]$ and are reported to exhibit facilitation in the Gambia [14] and Papua New Guinea [15]. This observation forms the basis of the strategy of the Global Programme to Eliminate Lymphatic Filariasis (GPELF) that 5-6 annual rounds of MDA to all at-risk populations in areas where the vectors exhibit facilitation e.g. transmission of $W$. bancrofti by Anopheles species, will lead to elimination [14,16,17].

A study in northern Ghana gave the first indication that members of the An. gambiae s.l. could be exhibiting limitation [5] which is a negative feedback mechanism whereby the number of ingested $\mathrm{mf}$ developing to infective stage (L3) decreases as the number of $\mathrm{mf}$ ingested increases $[12,13]$. However the authors of this study pooled the vectors An. gambiae s.l. and An. funestus together in the analysis to arrive at this conclusion because of the few numbers of mosquitoes obtained. Since then the individual species have not been studied further to determine vector competencies at low microfilaraemia levels.

Annual MDA has been ongoing in the Gomoa District, Ghana since 2001 and entomological monitoring of the impact has been conducted at eight sentinel communities in the District. After 6 rounds of MDA, the overall microfilariae $(\mathrm{mf})$ prevalence in the human population had decreased from $14 \%$ in 2001 to $0 \%$ in 2007 in the district (Boakye DA, unpublished report to WHO/TDR). However, this general reduction was not observed at some of the sites notably at Hwida but markedly so at another site, Mampong. The entomological monitoring at the two sites showed that at baseline,
Mampong had a human microfilaraemia level of $14 \%$ with An. gambiae s.l annual biting rate (ABR) of 56,164 bites/person/year and an ATP (annual transmission potential) of 129.29 infective larvae/person/year. At Hwida comparative values were An. gambiae s.l ABR of $411 /$ person/year with only infected mosquitoes (0.074) and none infective, and therefore an ATP of zero and human microfilaraemia of $12 \%$. After six MDAs the ABR, ATP and human microfilaraemia levels were 55,883/person/year, 15.21 infective larvae/person/year and $0 \%$ respectively at Mampong. At Hwida the corresponding values were 2494/person/year, 15.21 infective larvae/person/year and 3\% respectively. That the relatively small population size of An. gambiae s.l at Hwida was responsible for maintaining transmission there while the opposite held true at Mampong suggested to us that the two An. gambiae s.l populations could be different in their vectorial competencies with that at Hwida being more efficient at low level microfilaraemia i.e. exhibiting limitation. Earlier species identification during the monitoring period had indicated a mixture of An. gambiae s.s. and An. melas at Hwida and only An. gambiae s.s. at Mampong but these were not studied further.

This study therefore investigated the sibling species composition of An. gambiae complex and their cibarial armatures in terms of teeth numbers, and the sizes of the cibarium and the dome as surrogate determinants of their vectorial competencies.

\section{Methods \\ Study sites}

The endemic communities; Mampong $\left(05^{\circ} 24^{\prime} \mathrm{N}, 00^{\circ}\right.$ $\left.36^{\prime} \mathrm{W}\right)$ and Hwida $\left(05^{\circ} 15^{\prime} \mathrm{N}, 00^{\circ} 48^{\prime} \mathrm{W}\right)$ are located in the Gomoa District, which is approximately $80 \mathrm{~km}$ west of Accra, the capital city of Ghana.

Mampong is located near the Okyereko Irrigation Scheme which was created for rice farming. The irrigation scheme provides suitable breeding grounds for Anopheles mosquitoes [7] leading to a high density of Anopheles in the area. The estimated population size of Mampong is 960 inhabitants. Hwida is located on the coast of the Atlantic Ocean with an estimated population size of 456 inhabitants. A large man-made pond at Hwida, which serves as a source of water for the inhabitants, is a major feature of its landscape. The two communities are approximately $28 \mathrm{~km}$ apart and they both have the same vegetation which is coastal savannah. Previous studies have implicated An. gambiae s.l. and $A n$. funestus as the vectors of LF in the Gomoa District $[2,3]$.

\section{Mosquito sampling}

Mosquito surveys by hourly indoor human landing catches (HLC) were carried out simultaneously in the two 
communities from $1800 \mathrm{H}$ to $0600 \mathrm{H}$ a day each month from August to December 2007 by trained volunteers after obtaining ethical approval from the Institutional Review Board of the Noguchi Memorial Institute for Medical Research and consent from the volunteers. The sampling period was selected to correspond to the highest mosquito breeding season in the area, based on the previous sampling in the area. A household was selected randomly and a room used for collection each month; thus a total of 5 rooms were sampled per community. The mosquitoes were collected by two volunteers per community. Each mosquito was initially identified morphologically to An. gambiae s.l. $[18,19]$. The head of each An. gambiae s.l. mosquito was then separated from the rest of the body and stored in $1.5 \mathrm{ml}$ Eppendorf tubes containing silica gel until needed for the cibarial armature studies. The thorax and abdomen together were similarly kept in separate Eppendorf tubes until needed for the molecular identifications to sibling species and the $\mathrm{M}$ and $\mathrm{S}$ molecular forms.

\section{PCR identification of An. gambiae species and An.}

\section{gambiae s.s. molecular forms}

DNA extraction from homogenised thorax and abdomen tissue used the method of Collins et al. [20] and the PCR identification to species used the method of Scott et al. [21]. A restriction digest of the PCR product of identified An. gambiae s.s was then carried out to determine the molecular forms [22].

\section{Cibarial armature}

The head of each mosquito was placed in an appropriately labelled $0.5 \mathrm{ml}$ Eppendorf tube and three drops of clearing medium (equal volumes of chloral hydrate and phenol) was added and kept in the dark for 7 days. The head was removed and placed on a microscope slide and a drop of Puri's medium added [23]. In most instances, the position of the mount was manipulated until the ideal position that facilitated counting of the cibarial teeth was obtained before covering with a cover slip. The cibarial armature was then viewed under a compound microscope at $400 \times$ magnification. The number of cibarial teeth of each head was then counted and recorded. A $10 \mu \mathrm{m}$ (micrometer) eye piece gauge was used to measure the length and width of the cibarium and the cibarial dome for each mounted sample.

\section{Statistical analysis}

Univariate functions in SPSS version 11.5 for Windows ${ }^{\mathrm{mm}}$ (SPSS Inc, Cary, USA) were used to calculate the means, median, range and the standard deviations. Analysis of variance (ANOVA) was then used to test the significance of the comparative values obtained (significance: $\mathrm{p}<0.05)$.

\section{Results}

A total of 2553 mosquitoes were collected at Mampong of which 1087 (42.6\%) were An. gambiae s.l. Other mosquito species obtained were Culex spp. (29.9\%), Mansonia spp. (23.9\%), An. pharoensis (2.7\%), An. funestus (1.6\%) and Aedes spp. (0.1). Of the 1087 An. gambiae s.l collected, 290 were further examined with PCR and 280 (96.6\%) were all identified as An. gambiae s.s made up of $275(98.2 \%) \mathrm{M}$ and 5 (1.8\%) S molecular forms. Ten (3.4\%) specimens failed to amplify.

A total of 112 mosquitoes were collected at Hwida and 67 (59.8\%) were An. gambiae s.l. The other mosquito species obtained were distributed as follows; Culex spp. (29.5\%), Mansonia spp. (4.5\%), An. pharoensis (0.9\%), An. funestus (4.5\%) and Aedes spp. (0.9\%). The 67 An. gambiae s.l. comprised of 40 (59.7\%) An. melas, $24(35.8 \%)$ An. gambiae s.s and $3(4.5 \%)$ failed to amplify. Of the 24 An. gambiae s.s. 17 (71\%) were M molecular form and 7 (29\%) were S molecular form.

A total of 71 An. gambiae s.l. (35 An. melas and 36 An. gambiae s.s) were processed for the cibarial armature studies. However, the cibarial armatures of only 17 An. gambiae s.s. (11 M and $6 \mathrm{~S}$ molecular forms) and 13 An. melas could be read. A typical example of the cibarial armature of An. gambiae s.l is shown in figure 1 . The number of teeth counted for all the species were within 12 to 19 (Table 1). The observed difference in teeth numbers was significantly fewer ( $\mathrm{p}=0.004)$ in $A n$. melas than in An. gambiae s.s. There was, however, no significant difference in the number of teeth of the $M$ and S molecular forms of An. gambiae s.s ( $\mathrm{p}=0.503)$. The number of teeth of An. melas was, however, significantly fewer than An. gambiae M molecular form ( $\mathrm{p}=$ $0.032)$ and $\mathrm{S}$ molecular form $(\mathrm{p}=0.002)$.

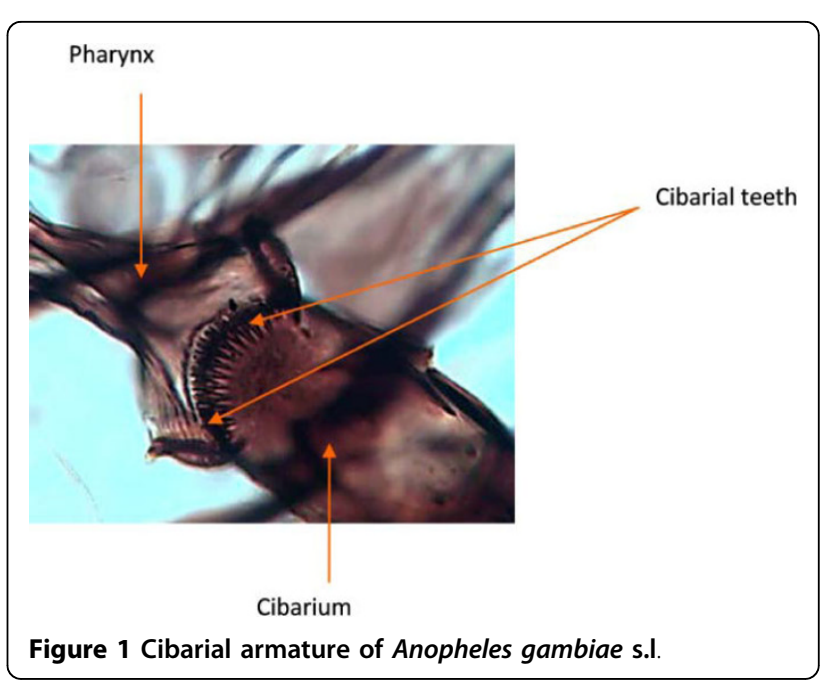


Table 1 Number of cibarial teeth, length and width of cibarial dome and cibarium of An. gambiae s.l

\begin{tabular}{|c|c|c|c|c|c|c|c|c|c|c|c|}
\hline Species & $\begin{array}{l}\text { Median teeth } \\
\text { number (range) }\end{array}$ & $\begin{array}{c}\text { Mean } \\
\text { number } \\
\text { of teeth }\end{array}$ & SD (Range) & $\begin{array}{l}\text { Mean } \\
\text { length of } \\
\text { dome } \\
(\mu \mathrm{m})\end{array}$ & SD (Range) & $\begin{array}{l}\text { Mean } \\
\text { width of } \\
\text { dome } \\
(\mu \mathrm{m})\end{array}$ & SD (Range) & $\begin{array}{l}\text { Mean } \\
\text { length of } \\
\text { cibarium } \\
(\mu \mathrm{m})\end{array}$ & SD (Range) & $\begin{array}{c}\text { Mean } \\
\text { width of } \\
\text { cibarium } \\
(\mu \mathrm{m})\end{array}$ & SD (Range) \\
\hline An. gambiae s.s & $15(13-19)$ & 15.7 & $\pm 1.54(13-19)$ & 1.04 & $\pm 0.12(0.8-1.2)$ & 1.73 & $\pm 0.21(1.2-2.4)$ & 4.12 & $\pm 0.48(3.2-4.8)$ & 2.32 & $\pm 0.31(1.6-2.8)$ \\
\hline$M$ form & $15(13-19)$ & 15.5 & $\pm 1.57(13-19)$ & 1.05 & $\pm 0.13(0.8-1.2)$ & 1.73 & $\pm 0.24(1.2-2.4)$ & 4.16 & $\pm 0.26(4.0-4.6)$ & 2.40 & $\pm 0.28(1.8-2.8)$ \\
\hline $\mathrm{S}$ form & $16(15-17)$ & 16.0 & $\pm 1.51(15-17)$ & 1.04 & $\pm 0.08(1.0-1.2)$ & 1.73 & $\pm 0.10(1.6-1.8)$ & 4.10 & $\pm 0.53(3.2-4.8)$ & 2.07 & $\pm 0.30(1.8-2.4)$ \\
\hline An. melas & $14(12-15)$ & 14.1 & $\pm 1.56(12-15)$ & 1.05 & $\pm 0.18(0.8-1.4)$ & 1.70 & $\pm 0.13(1.4-1.8)$ & 3.91 & $\pm 0.76(2.8-5.0)$ & 2.24 & $\pm 0.26(1.8-2.8)$ \\
\hline
\end{tabular}


There was no significant difference in the lengths and widths of both the cibarial dome and cibarium of $A n$. melas, $\mathrm{M}$ and $\mathrm{S}$ molecular forms of An. gambiae s.s ( $\mathrm{p}>$ 0.05).

\section{Discussion}

The ability of mosquito genera to transmit filarial parasites, particularly at low microfilaria density vary and three density-dependent processes; limitation, facilitation and proportionality have been described to explain them [14]. "Limitation" describes the situation where vectors are efficient even at very low parasite densities and "facilitation" for the vectors that are efficient mainly at high microfilaraemia levels. Anopheles species are considered to exhibit the process of facilitation $[14,16,17]$ and therefore it is assumed that low level microfilaraemia resulting from MDA would lead to interruption of transmission and elimination of lymphatic filariasis in anopheline transmission areas.

One factor that has been reported to influence the efficacy of vector species is the cibarial armature which is known to have lethal effect on ingested filarial parasites [10]. The fewer the ingested parasites the more pronounced the laceration effect by the cibarial armature since most will be effectively damaged. However as the ingested parasite numbers increase, this effect decreases since some parasites will mask the teeth thereby allowing others to pass through unscathed [24]. McGreevy et al. [10] surmised that the extensive variations observed in the size, shape and number of cibarial teeth of mosquitoes could be determinants of their vectorial efficiency. With this reasoning cibarial armature with low teeth numbers functions less as a barrier therefore vectors possessing this feature should transmit effectively even at low densities of ingested parasites.

The number of teeth reported by this study for the $A n$. gambiae species falls within the range of 12-20 that was reported for An. gambiae s.l [18]. However, this study did not distinguish the sibling species. In a later study, Bryan and Southgate [11] observed that An. melas destroyed relatively fewer numbers of microfilariae than An. gambiae s.s but did not give any reasons for this. In the present study we show that $A n$. melas possess significantly lower number of teeth than both $\mathrm{M}$ and $\mathrm{S}$ forms of $A n$. gambiae s.s. That An. melas possessed significantly lower number of cibarial teeth than An. gambiae s.s (the molecular forms included), is important information and explains for the first time the possibility that differences may exist in the vectorial competencies within the $A n$. gambiae sibling species complex in West Africa in the transmission of W. bancrofti. The fewer number of cibarial teeth in An. melas as observed may therefore make this species a more efficient vector particularly at low level microfilaraemia and thus exhibit limitation, while
An. gambiae s.s. on the contrary exhibit facilitation. This difference in vector capabilities at low microfilaraemia between the two vector species could therefore be relevant in explaining the different impact of the six rounds of MDA on transmission observed in the two communities being significantly reduced at Mampong but relatively unchanged at Hwida.

The results obtained by this study also add to the body of evidence that, at least in Ghana, not all Anopheles species may exhibit the process of facilitation. Moreover, that these two phenomena i.e. limitation and facilitation occur in communities that are in terms of distance very close $(28 \mathrm{~km})$ suggests that vectorial systems at the local level should be taken into account if LF elimination is considered. Vector control should therefore be considered in addition for areas where the principal vectors exhibit limitation as is found in the current study for An. melas.

Although An. funestus is a known vector of LF in Ghana, it was found in very low numbers and was therefore not considered to play any significant role to influence transmission in the two studied communities. However, in light of the results obtained it may be worthwhile to study this species especially in northern Ghana for example where it is a major vector of LF and limitation is suspected [5] but An. melas has not been reported there.

\section{Conclusion}

We observed from this study that An. gambiae s.s possess significantly more cibarial teeth than An. melas. This could explain the different impact observed after 6 MDAs at Mampong and at Hwida and the reported differences in the vectorial competencies within the $A n$. gambiae sibling species complex in West Africa in the transmission of $W$. bancrofti. We suggest that an understanding of the local vectorial system may therefore be necessary in areas where MDA alone is not achieving the goals of LF elimination.

\section{Acknowledgements}

This study was partly funded by a WHO/TDR grant award to DAB (WHO/TDR grant No. A000693). It was also funded through African Regional Postgraduate Programme for Insect Scientists (ARPPIS) by the International Institutes Cooperation Programme (SII), Netherlands. The technical support rendered by Alfred K. Dodoo, Isaac Odoi, Jewelna Osei-Poku, Kwame Desewu, Shirley Cameroon-Odoom, Bethel Kwansa-Bentum, Sakyi Kojo Yirenkyi, Sampson Otoo and Richard A. Akuffo of NMIMR and the cooperation of the chiefs, elders and community members at the study sites are fully acknowledged. We also are grateful to Professor Moses Bockarie for his comments on the manuscript. Professor Alexander Nyarko, Director of NMIMR is acknowledged for granting permission to publish.

\section{Author details}

'Department of Parasitology, Noguchi Memorial Institute for Medical Research, University of Ghana, P.O. Box LG 581, Legon, Accra, Ghana. ${ }^{2}$ WHOTDR, 1211 Geneva 27, Switzerland. 


\section{Authors' contributions}

All the authors have contributed significantly to this study. DAB and MDW contributed intellectually to the conceptualization, design of both the study and manuscript preparation. HA carried out the laboratory and field studies and manuscript preparation. All authors read and approved the final manuscript.

\section{Competing interests}

The authors declare that they have no competing interests.

Received: 2 June 2010 Accepted: 14 September 2010 Published: 14 September 2010

\section{References}

1. World Health Organization: Annual report on lymphatic filariasis 2001. Geneva 2002.

2. Dunyo SK, Appawu M, Nkrumah FK, Baffoe-Wilmot A, Pedersen EM, Simonsen PE: Lymphatic filariasis on the coast of Ghana. Trans $R$ Soc Trop Med Hyg 1996, 90:634-638.

3. Dzodzomenyo MD, Dunyo SK, Ahorlu CK, Coker WZ, Appawu MA Pedersen EM, Simonsen PM: Bancroftian filariasis in an irrigation project community in southern Ghana. Trop Med Int Health 1999, 4:13-18.

4. Appawu MA, Dadzie SK, Baffoe-Wilmot A, Wilson MD: Lymphatic filariasis in Ghana: entomological investigation of transmission dynamics and intensity in communities served by irrigation systems in the Upper East Region of Ghana. Trop Med Int Health 2001, 6:511-516.

5. Boakye DA, Wilson MD, Appawu MA, Gyapong J: Vector competence for Wuchereria bancrofti of the Anopheles populations in the Bongo district of Ghana. Ann Trop Med Parasitol 2004, 98(5):501-508.

6. Appawu MA, Baffoe-Wilmot A, Afari EA, Nkrumah FK, Petrarca V: Species composition and inversion polymorphism of the Anopheles gambiae complex in some sites of Ghana, West Africa. Acta Trop 1994, 56:15-23.

7. Okoye PN, Wilson MD, Boakye DA, Brown CA: Impact of the Okyereko irrigation project in Ghana on the risk of human malaria infection by Anopheles species (Diptera: Culicidae). Afr Entomol 2005, 13(2):249-253.

8. Yawson AE, Weetman D, Wilson MD, Donnelly MJ: Ecological zones rather than molecular forms predict genetic differentiation in the malaria vector Anopheles gambiae s.s. in Ghana. Genetics 2007, 175:751-761.

9. Bryan $\mathrm{JH}$, Southgate VA: Factors affecting transmission of Wuchereria bancrofti by Anopheles mosquitoes. 1. Uptake of microfilariae. Trans $R$ Soc Trop Med Hyg 1988, 82:128-137.

10. McGreevy PB, Bryan JH, Oothuman P, Kolstrup N: The lethal effects of the cibarial and pharyngeal armatures of mosquitoes on microfilariae. Trans R Soc Trop Med Hyg 1978, 72:361-368.

11. Bryan $\mathrm{JH}$, Southgate VA: Factors affecting transmission of Wuchereria bancrofti by Anopheles mosquitoes. 2. Damage to ingested microfilariae by mosquito foregut armatures and development of filarial larvae in mosquitoes. Trans R Soc Trop Med Hyg 1988, 82:138-145.

12. Bain O: Transmission des filarioses. Limitation des passages de microfilaires ingérées vers l'hémocèle des vecteurs; interprétation. Ann Parasitol Hum Comp 1971, 46:613-631.

13. Brengues J, Bain O: Passage des microfilaires de l'estomac vers I'hemocele du vecteur, dans les couples Wuchereria bancrofti - Anopheles gambiae A, Wuchereria bancrofti - Aedes aegypti et Setaria labiatopapillosa - Aedes aegypti. Cah O R S T O M Ser Entomol Med Parasitol 1972, 10:235-249.

14. Southgate BA, Bryan JH: Factors affecting transmission of Wuchereria bancrofti by anopheline mosquitoes. 4. Facilitation, limitation, proportionality and their epidemiological significance. Trans $R$ Soc Trop Med Hyg 1992, 86:523-530.

15. Bockarie MJ, Tisch DJ, Kastens W, Alexander ND, Dimber Z, Bockarie F, Ibam E, Alpers MP, Kazura JW: Mass treatment to eliminate filariasis in Papua New Guinea. N Engl J Med 2002, 347:1841-1848.

16. Weber RH: Can anopheline-transmitted filariasis be eradicated? J Trop Med Hyg 1991, 94:241-244.

17. Snow LC, Bockarie MJ, Michael E: Transmission dynamics of lymphatic filariasis: vector-specific density dependence in the development of Wuchereria bancrofti infective larvae in mosquitoes. Med Vet Entomol 2006, 20:261-272.
18. Gillies MT, De Meillon B: The Anophelinae of Africa South of the Sahara (Ethiopian Zoogeographical Region) South African Institute for Medical Research 1968

19. Gillies MT, Coetzee M: A supplement to the Anophelinae of Africa South of the Sahara (Afrotropical Region) South African Institute for Medical Research 1987.

20. Collins FH, Mendez MA, Rasmussen MO, Mehaffey PC, Besansky NJ, Finnerty $\mathrm{V}$ : A ribosomal RNA gene probe differentiates member species of the Anopheles gambiae complex. Am J Trop Med Hyg 1987, 37:37-41.

21. Scott JA, Brogdon WG, Collins FH: Identification of single specimens of the Anopheles gambiae complex by the polymerase chain reaction. Am J Trop Med Hyg 1993, 49(4):520-529.

22. Fanello C, Santolamazza F, della Torre A: Simultaneous identification of species and molecular forms of the Anopheles gambiae complex by PCRRFLP. Med Vet Entomol 2002, 16:461-464.

23. Smart J, Jordan K, Whittick RJ: Insect of Medical Importance. Adlen Press: Oxford, 41965.

24. Duerr H, Dietz K, Schulz-Key H, Büttner DW, Eichner M: Determinants of the eradicability of filarial infections: a conceptual approach. Trends Parasitol 2005, 21:88-96.

doi:10.1186/1756-3305-3-85

Cite this article as: Amuzu et al:: Studies of Anopheles gambiae s.l (Diptera: Culicidae) exhibiting different vectorial capacities in lymphatic filariasis transmission in the Gomoa district, Ghana. Parasites \& Vectors 2010 3:85.

\section{Submit your next manuscript to BioMed Central and take full advantage of:}

- Convenient online submission

- Thorough peer review

- No space constraints or color figure charges

- Immediate publication on acceptance

- Inclusion in PubMed, CAS, Scopus and Google Scholar

- Research which is freely available for redistribution

Submit your manuscript at www.biomedcentral.com/submit
C) Biomed Central 